\title{
Inclusão em Escolas das Águas do Pantanal: entre influências globais e particularidades locais
}

\author{
Inclusion in 'Escolas das Águas' in Pantanal (Brazil): global influences and \\ local peculiarities
}

Inclusión en las Escuelas de las Aguas del Pantanal (Brasil): entre influencias globales y peculiaridades locales

Washington Cesar Shoiti Nozu

Professor doutor na Universidade Federal da Grande Dourados, Dourados, Mato Grosso do Sul, Brasil. washingtonnozu@ufgd.edu.br

ORCID - http://orcid.org/0000-0003-1942-0390

\section{Mônica de Carvalho Magalhães Kassar}

Professora doutora na Universidade Federal de Mato Grosso do Sul, Corumbá, Mato Grosso do Sul, Brasil. monica.kassar@gmail.com

ORCID - http://orcid.org/0000-0001-5577-6269

Recebido em 4 de agosto 2020

Aprovado em 17 de agosto de 2020

Publicado em 17 de novembro de 2020

\section{RESUMO}

A educação inclusiva tem propiciado, no Brasil, o crescimento do número de matrículas de alunos com Necessidades Educacionais Especiais (NEE) - dentre eles o Público-Alvo da Educação Especial - nas escolas comuns/regulares, inclusive naquelas localizadas em regiões distantes de núcleos urbanos. Em atenção a esse panorama, este texto objetivou analisar as condições de acesso e de permanência desses alunos nas Escolas das Águas do Pantanal sul-mato-grossense. Os caminhos investigativos ancoraram-se em uma perspectiva qualitativa, aproximando-se da Abordagem do Ciclo de Políticas e da Teoria da Atuação. O campo empírico foi constituído pelas Escolas das Águas da rede municipal de ensino de Corumbá/MS. Os procedimentos de coleta de dados envolveram: revisão bibliográfica, análise documental, observação do trabalho da equipe gestora, visitas a unidades de ensino e entrevistas semiestruturadas realizadas com 26 profissionais das Escolas das Águas. As análises consideraram aspectos relacionados à organização administrativa escolar, às características de acesso à escola e às percepções dos professores e gestores sobre a permanência dos alunos nas unidades de ensino, contexto das práticas. Verificou-se que os estudantes com NEE estão chegando às Escolas das Águas. Sua presença tem provocado estranhamentos, mas também a percepção de que tal condição é mais um desafio diante de um universo tão diverso.

Palavras-chave: Educação inclusiva; Educação Especial; condições de acesso e permanência na escola.

\section{ABSTRACT}

In Brazil, inclusive education has produced an increase in the number of enrollments of students with Special Educational Needs (SEN), in ordinary/regular schools, including the 
ones localized in regions far from urban centers. Regarding that scenario, the paper aimed to analyze the conditions of access and permanence of these students in riverside schools - Escolas das Águas - in the Pantanal of Mato Grosso do Sul. The qualitative research was based on the Policy Cycle Approach and the Theory of Enactment. The empirical field were the municipal schools called Escolas das Águas, located in Corumbá/MS (Brazil). The data collection involved bibliographic review, document analysis, the observation of school managers' work, visits to schools, and semi-structured interviews with 26 professionals of the Escolas das Águas. The analyses considered aspects related to the school administrative organization, the characteristics of school access, and the perceptions of teachers and school managers regarding the permanence of students in the school units. As observed, students with SEN have been attending classes at the Escolas das Águas. Their presence has caused a feeling of unfamiliarity, but also the perception that the condition is one of the challenges in such a diverse universe.

Keywords: Inclusive education; Special Education; conditions for access and permanence at school.

\section{RESUMEN}

La educación inclusiva en Brasil ha llevado un aumento en el número de inscripciones de alumnos con Necesidades Educativas Especiales (NEE) en escuelas ordinarias/regulares, incluso en las ubicadas en regiones alejadas de los centros urbanos. Ante este panorama, este texto tuvo como objetivo analizar las condiciones de acceso y permanencia de estos estudiantes en las escuelas ribereñas del Pantanal Sul-Mato Grosso, las Escolas das Águas (Escuelas de Aguas). Los caminos de investigación se anclaron en un enfoque cualitativo, tomando la colaboración del Abordaje de los Ciclos de Políticas y da Teoría de la Actuación. El campo empírico fue constituido por las Escolas das Águas de Corumbá/MS (Brasil). Los procedimientos de recolección de datos se constituyeron en: revisión de literatura, análisis de documentos, observación de trabajo de la equipe gestora de las escuelas, visitas a las unidades de enseñanza y entrevistas semiestructuradas con 26 profesionales de las Escolas das Águas. Los análisis consideraron aspectos relacionados con la organización administrativa escolar, las características de acceso a la escuela y las percepciones de los docentes y directivos sobre la permanencia de los alumnos en las unidades escolares, el contexto de las prácticas. Se verificó que los estudiantes con NEE estaban llegando a las Escolas das Águas. Su presencia había provocada extrañeza, pero también la percepción de que tal condición es más un desafío frente a un universo muy diverso.

Palabras clave: Educación inclusiva; Educación Especial; condiciones de acceso y permanencia en la escuela.

\section{Desacostumando as palavras ${ }^{1}$}

Então era preciso desver o mundo para sair daquele lugar imensamente e sem lado.

Manoel de Barros (2015, p. 14).

A incorporação da abordagem inclusiva nas políticas educacionais brasileiras é permeada de influências internacionais, materializadas por meio de conferências e de declarações sobre a democratização do ensino - promovidas pela Organização das Nações 
Unidas para a Educação, a Ciência e a Cultura (UNESCO) - e por pressões de agências financeiras multilaterais, como o Banco Mundial e a Comissão Econômica para a América Latina e o Caribe (CEPAL) (GARCIA, 2010; KASSAR, 2011).

A Declaração de Salamanca, tida como um marco desse movimento para o atendimento às Necessidades Educacionais Especiais ${ }^{2}$ (NEE), exorta a escola comum a "acoger a niños discapacitados y niños bien dotados a niños que viven en la calle y que trabajan, niños de poblaciones remotas o nómadas, niños de minorías lingüísticas étnicas o culturales y niños de otros grupos o zonas desfavorecidos o marginados" (UNESCO, 1994, p. 6).

Essa orientação internacional foi traduzida e (re)interpretada com múltiplos sentidos, a partir das condições políticas, sociais, econômicas e culturais dos diferentes países (BUENO, 2008; GARCIA, 2010; MENDES; CABRAL, 2014). No Brasil, a despeito da abrangência dos princípios educacionais e da população compreendida pela Declaração de Salamanca, a produção textual oficial passou a restringir as políticas de inclusão ao âmbito da Educação Especial ${ }^{3}$ (BUENO, 2008). Tais políticas têm induzido, por meio de programas e de recursos financeiros, desde o início dos anos 2000, a escolarização dos estudantes da Educação Especial na rede regular de ensino, mantendo, contudo, a coexistência histórica dos atendimentos em escolas especiais (KASSAR, 2011; MENDES; CABRAL, 2014; REBELO; KASSAR, 2017).

Em 2008, a Política Nacional de Educação Especial na Perspectiva da Educação Inclusiva, articulando conceitos de Educação Inclusiva ${ }^{4}$ e de Educação Especial ${ }^{5}$, retomou ${ }^{6}$ a delimitação do Público-Alvo da Educação Especial (PAEE), já utilizada na educação brasileira, considerando os alunos com deficiência, transtornos globais do desenvolvimento $^{7}$ e altas habilidades/superdotação (BRASIL, 2008). Essa política e a produção normativa subsequente, almejando o acesso, a participação e a aprendizagem do PAEE nas escolas comuns, têm focalizado a oferta de Atendimento Educacional Especializado (AEE) $)^{8}$, sobretudo nas Salas de Recursos Multifuncionais (SRM) ${ }^{9}($ MENDES; CABRAL, 2014; REBELO; KASSAR, 2017).

Embora haja, mormente nos textos orientadores e normativos, a intenção de alinhamento nacional da política de inclusão, no contexto da prática, os sistemas de ensino e as escolas (re)criam a proposta de acordo com suas histórias, realidades e recursos (PRIETO, 2009; PAVEZI; MAINARDES, 2019). Em certa medida, pelo fato de que "as políticas educacionais, de modo geral, não atendem às especificidades regionais" 
http://dx.doi.org/10.5902/1984686X49204

(OLIVEIRA, 2016, p. 329). Assim, sensíveis aos desdobramentos das relações globaislocais, parafraseamos a poesia de Manoel de Barros, a qual descerra esta seção introdutória, com o intuito de "desver" as políticas de um "lugar imensamente e sem lado" e contextualizá-las em determinado tempo e espaço.

Lançamos o nosso olhar, assim, para a atuação da política de inclusão escolar em uma região bastante peculiar e reconhecida internacionalmente por ser uma das maiores planícies inundáveis do mundo: o Pantanal (AGÊNCIA NACIONAL DAS ÁGUAS et al., 2004). Para Ball, Maguire e Braun (2016, p. 18), a Teoria da Atuação busca

[...] compreender e documentar as maneiras pelas quais as escolas realmente lidam com demandas de políticas múltiplas e, às vezes, opacas e contraditórias, e as diversas maneiras que elas criativamente trabalham para fabricar e forjar práticas fora dos textos de política e ideias de políticas em função de suas realidades situadas - um processo de recontextualização que produz algum grau de heterogeneidade na prática.

Neste artigo, particularmente, atentamo-nos a um conjunto de unidades de ensino, localizadas em comunidades pantaneiras do município de Corumbá, Mato Grosso do Sul, denominadas de Escolas das Águas, para analisar as condições de acesso e de permanência de estudantes com NEE.

Salientamos que a adoção da terminologia $\mathrm{NEE}^{10}$ é: a) intencional, já que a sua amplitude abrange o PAEE presente nas Escolas das Águas; b) pautada na documentação político-normativa municipal e escolar que faz uso dessa denominação; c) justificada pelo contexto investigado, no qual muitos estudantes são identificados com características diferenciadas de comportamento e de aprendizagem, a partir da percepção de gestores e professores das Escolas das Águas, sem, contudo, um laudo clínico ou um parecer educacional especializado que os enquadrem como PAEE. De todo modo, esclarecemos que $\mathrm{o}$ atendimento da Educação Especial disponível nas Escolas das Águas, no período compreendido pela pesquisa, tinha como destinatário um aluno definido como PAEE.

\section{Trajetórias investigativas: nos emaranhos das Águas}

Os adejos mais raros se escondem nos emaranhos. Manoel de Barros (2017, p. 73).

Os caminhos investigativos que percorremos seguiram as trilhas da pesquisa qualitativa, que auxilia, conforme Esteban (2010), a compreensão de fenômenos educativos e a construção de um conjunto organizado de conhecimentos: 
http://dx.doi.org/10.5902/1984686X49204

Uma característica fundamental dos estudos qualitativos é sua atenção ao contexto; a experiência humana se perfila e tem lugar em contextos particulares, de maneira que os acontecimentos e fenômenos não podem ser compreendidos adequadamente se são separados daqueles (ESTEBAN, 2010, p. 129).

A escolha dessa abordagem fundamentou-se na aproximação ao contexto de unidades de ensino denominadas localmente como Escolas das Águas, vinculadas à Rede Municipal de Ensino (REME) ${ }^{11}$, de modo a compreender - poeticamente com Manoel de Barros e teoricamente com Stephen J. Ball e colaboradores - os "adejos" dos agentes da prática e seus sentidos e construções sobre a inclusão de alunos com NEE nos "emaranhos" cotidianos. O olhar para o contexto das práticas conforma-se em uma perspectiva segundo a qual a 'implementação' de políticas públicas é processo complexo, não linear, em que podem ser identificados 'ciclos', Ciclos de Políticas, permeados por vários contextos (BOWE; BALL; GOLD, 1992; MAINARDES, 2006).

A coleta de dados deu-se no segundo semestre de 2019 e no primeiro semestre de 2020, sendo esta última etapa afetada pela pandemia ocasionada pela COVID-19. Nesse interstício, procuramos reunir informações por meio de: a) revisão bibliográfica; b) levantamento e análise de documentação; c) observação do trabalho da equipe gestora das Escolas das Águas; d) visitas a cinco das nove unidades de ensino ${ }^{12}$; e) entrevistas semiestruturadas, a partir de um roteiro de 14 perguntas, com a Diretora Escolar e três Coordenadoras Pedagógicas; f) entrevistas semiestruturadas, mediante um roteiro de 15 perguntas, com 20 Professores Regentes e uma Professora Especialista em Educação Especial, que atuaram nas nove unidades de ensino no ano de 2019; e, g) entrevista aberta com uma Assistente de Secretaria. Assim, ao todo, contamos com a participação de 26 profissionais das Escolas das Águas, que tomaram ciência e, voluntariamente, concordaram em contribuir com a pesquisa por meio de Termo de Consentimento Livre e Esclarecido.

As entrevistas foram realizadas, inicialmente, na sede administrativo-pedagógica, localizada no núcleo urbano de Corumbá, e nas dependências das Escolas das Águas. A partir do contexto pandêmico, recorremos ao aplicativo WhatsApp, com gravação em áudio e posterior transcrição e textualização, objetivando a supressão de expressões típicas da linguagem oral. Em respeito ao sigilo das identidades, os participantes foram grafados como: Diretora Escolar - DE; Coordenadoras Pedagógicas - CP1, CP2 e CP3; Professores Regentes - PR, com diferenciação por meio de numerais de 1 a $3^{13}$, em seguida, o nome da unidade de ensino; Professora Especialista - PE; Assistente de Secretaria - AS. Quando 
http://dx.doi.org/10.5902/1984686X49204

duas ou mais integrantes da Direção e da Coordenação Pedagógica ofereceram a mesma informação, sinalizamos como um dado da Equipe Gestora. Após a sigla do participante, aparece o ano em que a informação foi prestada - 2019 ou 2020. Todos os nomes dos alunos constantes no artigo são fictícios. Os dados coletados mediante observação e visitas foram indicados, no decorrer do texto, com a sigla RDC (Registro de Diário de Campo), seguida do ano 2019 ou 2020.

\section{Escolas das Águas: caminhos, singularidades e contingências}

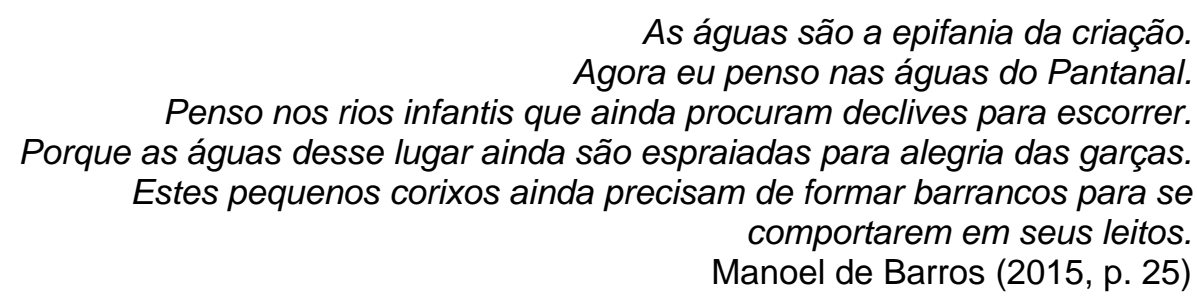

As palavras do nosso poeta guiam-nos a pensar nas especificidades da educação dos povos das águas e sua relação com a fisiografia do Pantanal. Isso porque o fluxo do rio Paraguai e de seus afluentes condiciona a vida das comunidades do Pantanal corumbaense (RIOS, 2020). O trabalho, o deslocamento, a moradia, a sociabilidade e a escolarização dos pantaneiros acompanham e se transmutam conforme a dinâmica dos ciclos de cheias e de secas dos rios.

Nas comunidades das águas corumbaenses habitam ribeirinhos, pescadores artesanais e profissionais, coletores de iscas para a pesca, trabalhadores rurais assalariados e pequenos agricultores (ZERLOTTI, 2014; MELO, 2017; OLIVEIRA, 2018; RIOS, 2020). Esses moradores são identificados como membros de povos e comunidades tradicionais (ECOA, 2010; CORUMBÁ, 2017a).

Além da exuberância natural amplamente disseminada nesse bioma brasileiro, as pesquisas alertam para a fragilidade da efetivação de políticas sociais, sobretudo quanto à saúde, educação, assistência social, habitação, saneamento básico e energia elétrica (ECOA, 2010; ZERLOTTI, 2014; ABREU, 2018; CRUZ, 2018; RIOS, 2020). A renda das famílias é de até um salário mínimo, em muitas comunidades (ECOA, 2010; MELO, 2017; OLIVEIRA, 2018). A variação da renda vincula-se principalmente à sazonalidade da pesca (ECOA, 2010). Muitas famílias são pensionistas e beneficiárias de programas assistenciais (CORUMBÁ, 2017a; ABREU, 2018). A escolaridade dos moradores é baixa, com pessoas 
http://dx.doi.org/10.5902/1984686X49204

analfabetas e/ou somente com os primeiros anos do Ensino Fundamental (ECOA, 2010; ZERLOTTI, 2014; ABREU, 2018; OLIVEIRA, 2018).

Sobretudo a partir do início dos anos 2000, uma série de ações esporádicas vem sendo realizada na região pelo poder público local, pela Marinha e por organizações não governamentais (ECOA, 2010; CRUZ, 2018). Em 2009, iniciaram-se as atividades do Programa Povo das Águas, visando a "articulação das políticas sociais, em interface com os órgãos de educação, saúde, assistência social, gestão governamental, infraestrutura, meio ambiente e desenvolvimento sustentável" (CORUMBÁ, 2012, p. 4).

As ações da administração municipal utilizam uma classificação própria das regiões, a saber: Baixo Pantanal, a $280 \mathrm{~km}$ do Porto Geral da cidade - com cerca de 233 famílias (699 pessoas); Médio Pantanal, a 180 km - em torno de 220 famílias (627 pessoas); e Alto Pantanal, a $320 \mathrm{~km}$ - por volta de 198 famílias (740 pessoas) (CORUMBÁ, 2012; 2015).

No ano de 2019, havia nove unidades de ensino compreendidas como Escolas das Águas e divididas entre polos ou extensões. Embora todas as unidades de ensino possuíssem estruturas físicas independentes, as extensões vinculavam-se, administrativamente, às definidas como polos (OLIVEIRA, 2018). As nove unidades de ensino estavam distribuídas nas três regiões, conforme a descrição da Figura 1:

Figura 1 - Escolas das Águas do Pantanal de Corumbá (2019)

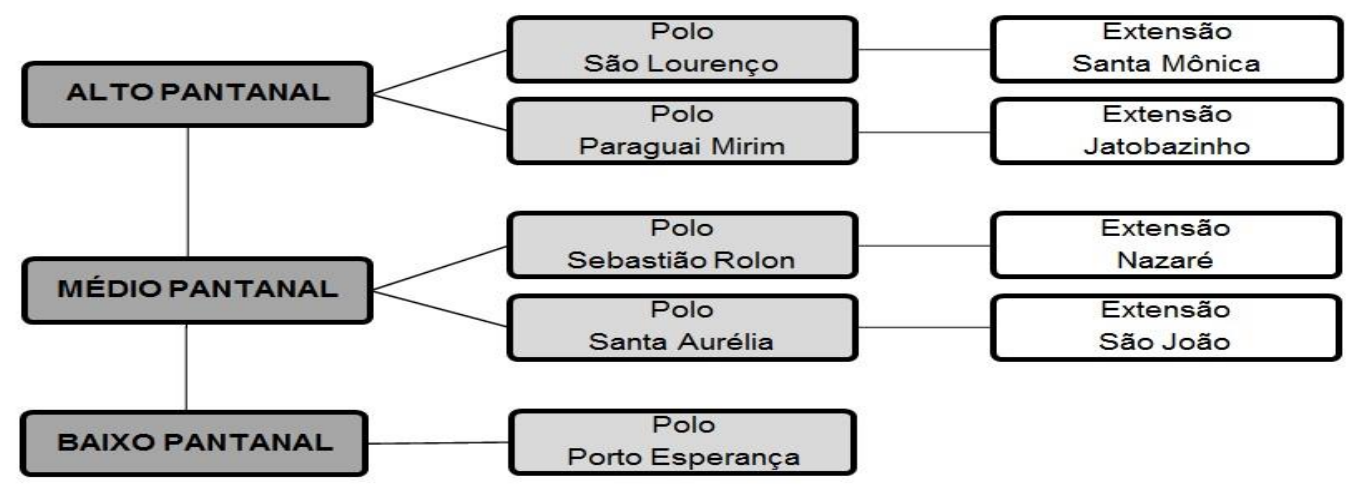

Fonte: Dados da pesquisa, elaboração de Eduardo Adão Ribeiro (2020).

Algumas pesquisas têm evidenciado a mutabilidade do número de unidades polos e extensões nos últimos anos (MELO, 2017; OLIVEIRA, 2018). As (re)configurações resultam das políticas de governo, particularmente nas (re)estruturações da Secretaria Municipal de Educação, além das demandas das comunidades das águas, pelo provimento do direito à educação. Nesses movimentos, unidades de ensino são criadas, reagrupadas, desativadas 


\section{Educação Especial}

http://dx.doi.org/10.5902/1984686X49204

ou extintas. A Figura 2 mostra a espacialização das unidades de ensino que funcionaram no ano de 2019.

Figura 2 - Espacialização das Escolas das Águas
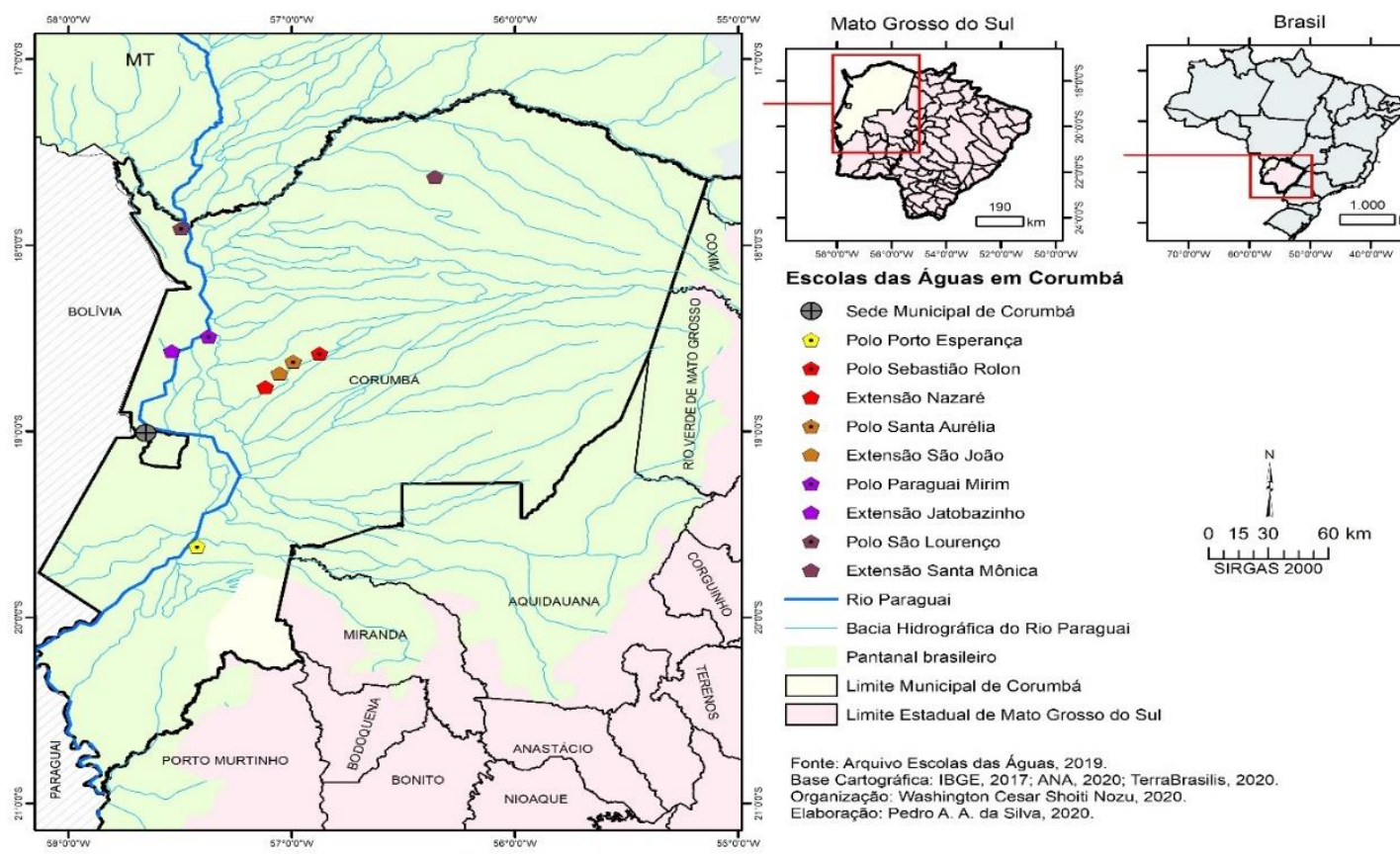

Fonte: Arquivo das Escolas das Águas, elaboração de Pedro A. A. da Silva (2020).

O município de Corumbá possui área total de $64.438,363$ km² (IBGE, 2019), sendo que $96,5 \%$ de seu território se encontra no Pantanal (GONÇALVES, 2019), que está dividido, hegemonicamente, em grandes propriedades privadas - fazendas - e em algumas unidades de proteção ambiental (ECOA, 2010; GONÇALVES, 2019). Sob o ponto de vista fisiográfico, de acordo com Zerlotti (2014, p. 22), "o Pantanal não é um ecossistema homogêneo, pois há muitas variações de uma região para outra da planície. Cada tipo possui um período de inundação, um tipo de solo, de relevo e vegetação".

Os trânsitos no Pantanal para as Escolas das Águas constroem-se, como nos inspira Manoel de Barros (2017, p. 62), por "muitos caminhos - nenhum caminho". Isso porque as rotas são alteradas e/ou interditadas a depender do regime pluvial e fluvial, constituindo-se um dos desafios cotidianos da mobilidade pantaneira. llustrativamente, em nossas viagens às unidades de ensino do Baixo e Médio Pantanal, a CP1-2019 nos alertava: "preparemse! Nós sabemos a data de saída [da área urbana] para as Escolas das Águas; a data de retorno é incerta".

A locomoção, no Pantanal, é feita por meios terrestres, fluviais e aéreos, com o uso de cavalos, tratores, carros com tração, bem como 'canoas de um pau' (de produção 
http://dx.doi.org/10.5902/1984686X49204

artesanal), as 'rabetas' (canoas com motor econômico), as 'voadeiras' (barcos movidos a motor), as 'freteiras' (embarcações de médio porte de transporte de cargas e passageiros)" (NOZU; KASSAR, 2020, p. 7) e aeronaves de pequeno porte (MELO, 2017). Alguns caminhos pantaneiros para as Escolas das Águas foram registrados na Figura 3.

Figura 3 - Mosaico dos Caminhos para as Escolas da Água

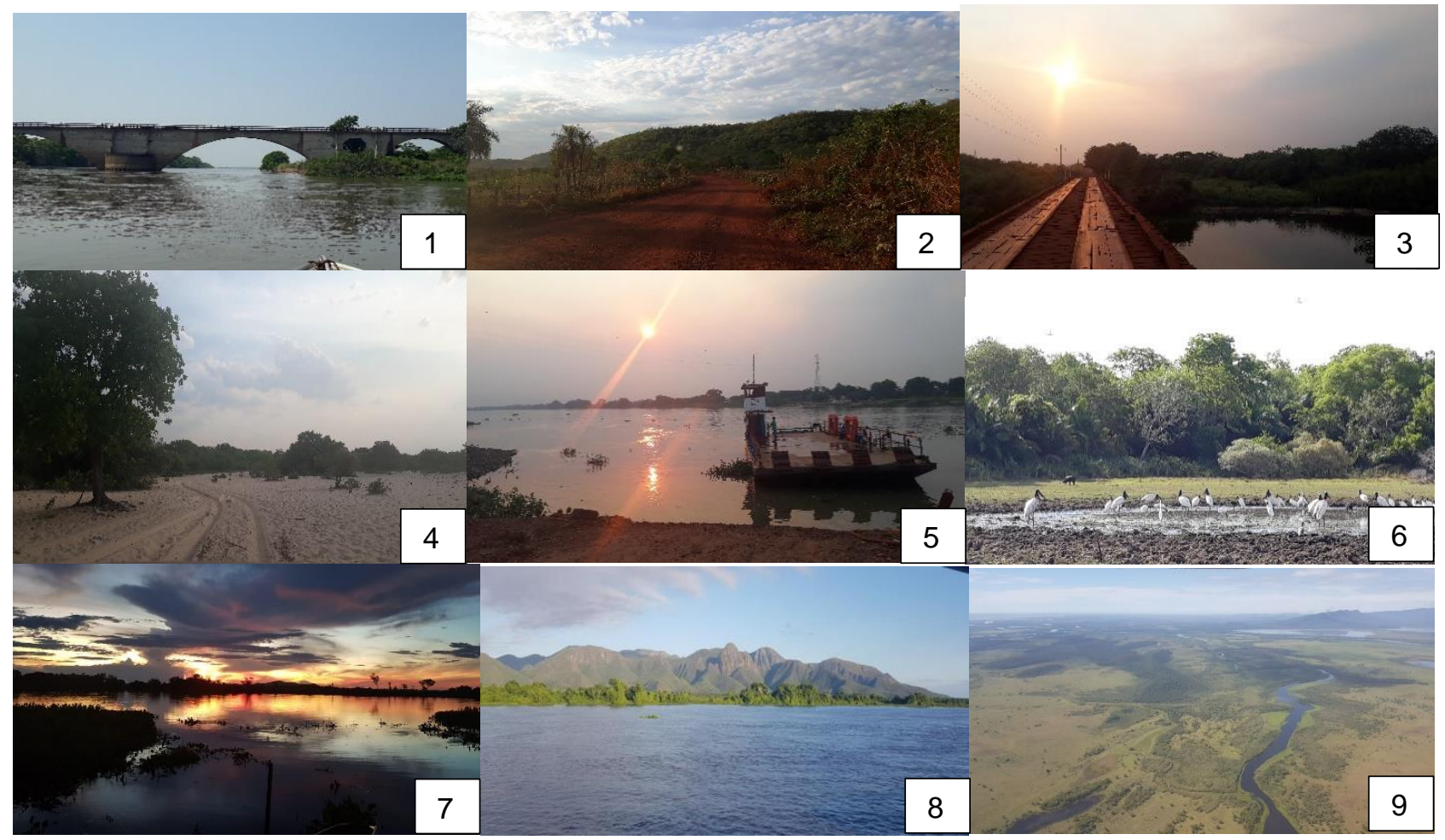

Fonte: 1, 2, 3, 4, 5 e 6 - Arquivo dos autores (2019); 7, 8 e 9 - Arquivo das Escolas das Águas (2019). Legenda: 1 - Caminhos no Baixo Pantanal; 2, 3, 4, 5 e 6 - Caminhos no Médio Pantanal; 7, 8 e 9 Caminhos no Alto Pantanal.

A heterogeneidade do Pantanal também atravessa a natureza jurídica, a gestão, a estrutura e o regime de funcionamento das Escolas das Águas. Das nove unidades de ensino, sete são mantidas com recursos do poder público municipal, ao passo que duas Jatobazinho $^{14}$ e Santa Mônica ${ }^{15}$ - são constituídas por parcerias público-privadas (MELO, 2017; OLIVEIRA, 2018; RIOS, 2020). A gestão das Escolas das Águas se dá por uma equipe composta por uma diretora e três coordenadoras pedagógicas, cuja sede administrativo-pedagógica está localizada no perímetro urbano do município de Corumbá. Esse grupo gestor conta com o trabalho de uma secretária e duas assistentes de secretaria, para as demandas de registros, documentações, transportes, merendas, materiais didáticos, entre outros, conforme nos inteirou a AS-2019. Periodicamente, membros dessa equipe deslocam-se para atendimentos itinerantes junto às unidades de ensino, verificando 
http://dx.doi.org/10.5902/1984686X49204

in locu as necessidades, as dificuldades e as alternativas para o processo de ensino e de aprendizagem (NOZU; KASSAR, 2020). Excepcionalmente, a unidade de Jatobazinho conta com coordenação pedagógica permanente, exercida cumulativamente por um dos professores, com projetos e materiais didáticos também diferenciados em relação às demais unidades de ensino.

As estruturas físicas das Escolas das Águas são diversas: algumas de alvenaria, outras de madeiras; construídas em palafitas ou em "terra firme"; às margens, sobre ou nas imediações dos rios (RDC-2019). A Figura 4 exibe fotografias das nove unidades de ensino.

Figura 4 - Mosaico das Escolas das Águas

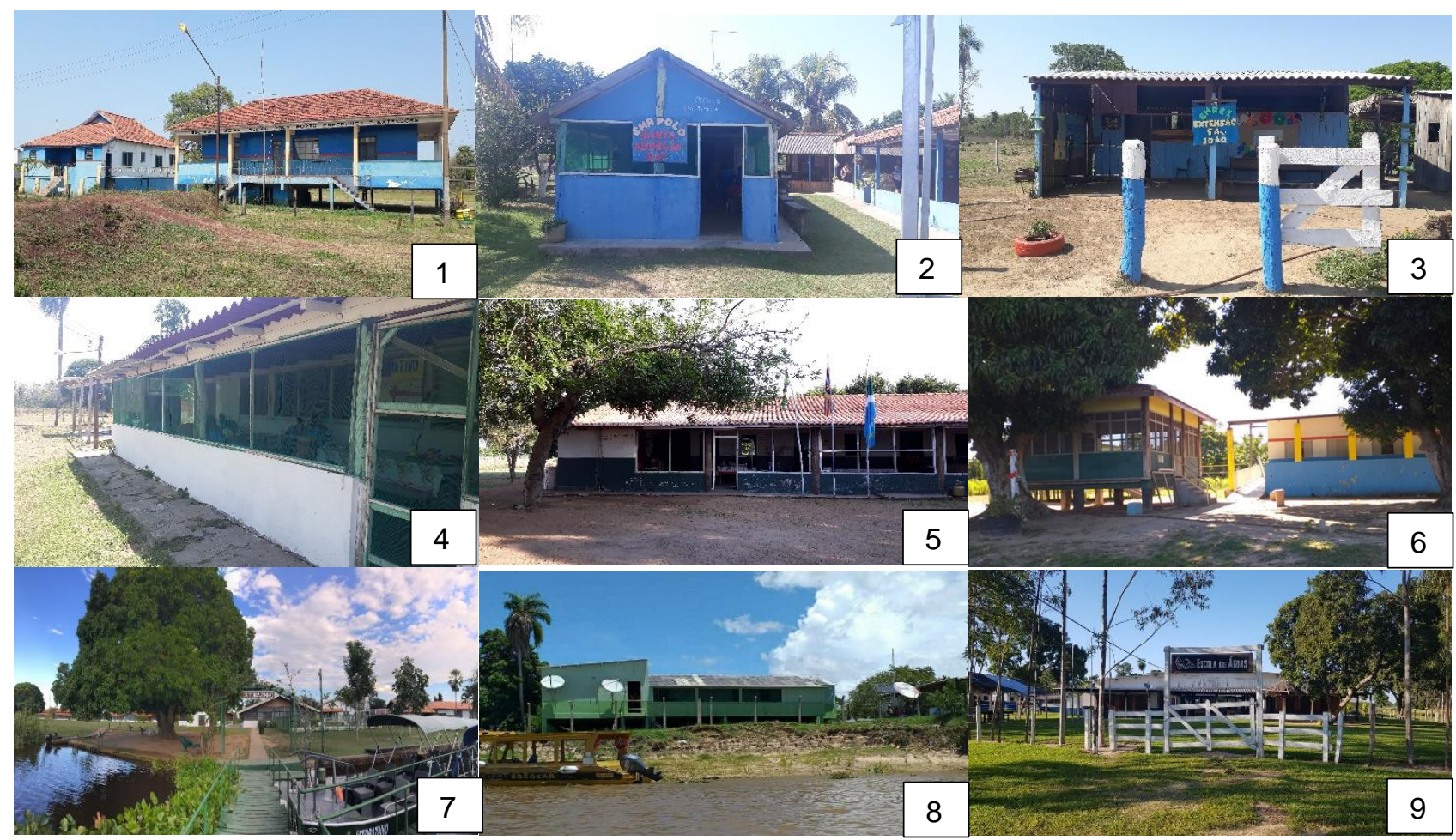

Fonte: 1, 2, 3, 4 e 5 - Arquivo dos autores (2019); 6, 8 e 9 - Arquivo das Escolas das Águas (2019); 7 Arquivo do Instituto Acaia (2019). Legenda: 1 - Polo Porto Esperança; 2 - Polo Santa Aurélia; 3 - Extensão São João; 4 - Polo Sebastião Rolon; 5 - Extensão Nazaré; 6 - Polo Paraguai Mirim; 7 - Extensão Jatobazinho; 8 - Polo São Lourenço; 9 - Extensão Santa Mônica.

Os desafios para a escolarização de crianças e de adolescentes pantaneiros são complexos e contínuos, dados os aspectos ambientais, sociais, econômicos, culturais e curriculares (ZERLOTTI, 2014; RIOS, 2020; NOZU; KASSAR, 2020). Em 2019, todas as unidades sob administração exclusivamente pública ofertaram os anos iniciais e finais do Ensino Fundamental, sendo que três delas possuíam Educação Infantil. As escolas sob administração público-privada ofertaram os anos iniciais do Ensino Fundamental e uma delas também Educação Infantil. 
A ampliação da oferta de escolarização nas Escolas das Águas é ação que data da última década. Até o ano de 2010, apenas três das nove unidades dispunham de turmas nos anos finais do Ensino Fundamental (CORUMBÁ, 2019a). Já a disponibilização do Ensino Médio, que na região está sob a responsabilidade da Secretaria de Estado de Educação, não tem ocorrido nas Escolas das Águas, tornando-se uma necessidade premente, sobretudo em virtude da política educacional de universalização da Educação Básica no Brasil. Diante dessas condições, "a criança se depara com duas alternativas: continua na comunidade com o pouco estudo que conseguiu adquirir ou segue para a cidade para dar continuidade aos estudos" (ECOA, 2010, p. 16).

Considerando as singularidades locais, em 2019, foram elaborados seis calendários para as nove unidades de ensino, com períodos de início e de término distintos. Ainda assim, todos previam 200 dias letivos (CORUMBÁ, 2019b). Para o trabalho escolar, duas unidades organizaram-se em regime regular de ensino, ao passo que as demais atuaram em tempo integral. As turmas caracterizaram-se, predominantemente, em multisseriadas, situação encontrada como o formato hegemônico de escolarização em territórios rurais por Hage e Reis (2018) e Oliveira (2016).

Em setembro de 2019, as matrículas nas unidades de ensino variaram entre 11 a 50 alunos, sendo o total de 293 matrículas nas Escolas das Águas (CORUMBÁ, 2019c). Os números são cambiantes ao longo do ano, em razão do êxodo rural, da evasão, da dificuldade de locomoção e do período da Piracema - em que muitos moradores se deslocam com seus filhos para a sede urbana do município (ECOA, 2010; RIOS, 2020).

Segundo as informações da Equipe Gestora, em 2019, aos alunos que residiam nas imediações das unidades de ensino - cujo trajeto casa-escola e vice-versa pudesse ser feito no tempo de até uma hora - era disponibilizado o transporte escolar diário. Em face da geografia física do Pantanal, o transporte dos alunos nas Escolas das Águas era realizado pelo "barco escola" e pelo "trator com carretinha", vistos na Figura 5. 
http://dx.doi.org/10.5902/1984686X49204

Figura 5 - Transportes das Escolas das Águas

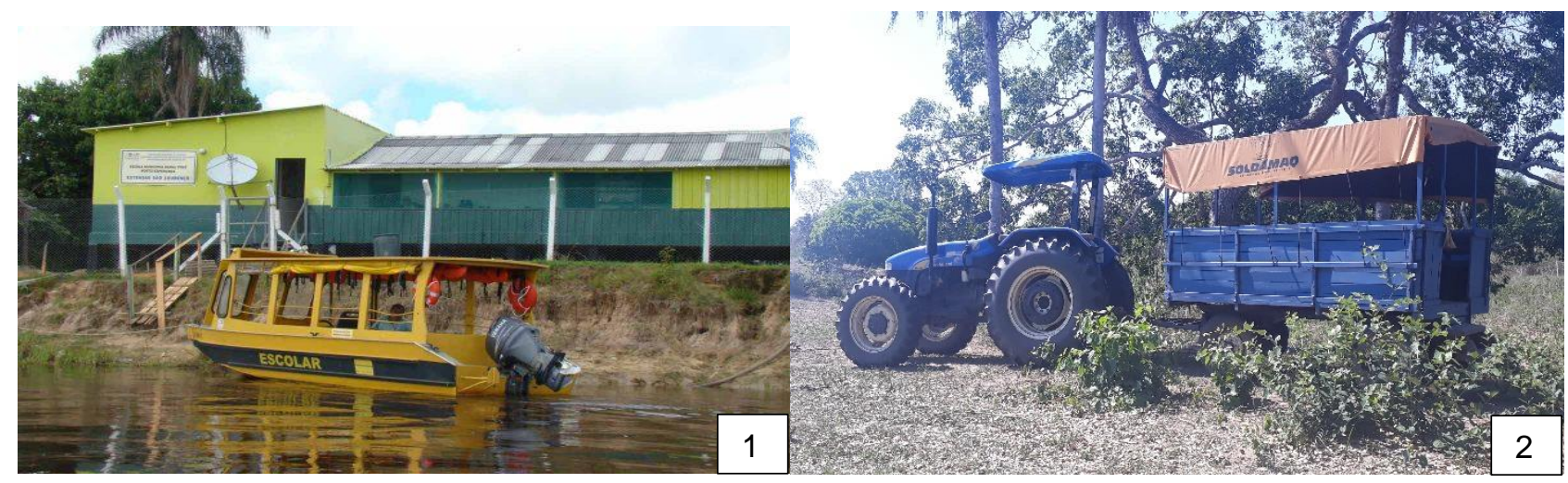

Fonte: 1 - Arquivo Escolas das Águas (2019); 2 - Arquivo dos autores (2019). Legenda: 1 - "Barco escola"; 2 - "Trator com carretinha".

Muitos alunos, contudo, residem a longas distâncias das Escolas das Águas (MELO, 2017; CRUZ, 2018). Para esses casos, algumas unidades de ensino dispõem de alojamentos estudantis, "tendo em vista o acesso que pode levar horas navegando de barco sob sol escaldante e/ou o enfrentamento de chuvas constantes com impossibilidade de navegação devido as cheias" (RIOS, 2020, p. 50). No ano de 2019, três escolas ofereciam internato semanal e duas ofertavam internato bimestral, com possibilidade de os alunos receberem visitas dos pais aos domingos (MELO, 2017). Nas unidades com alojamentos estudantis há monitores para as atividades não pedagógicas e da vida cotidiana.

O trabalho pedagógico nas Escolas das Águas contava, em 2019, com a atuação de 35 professores, do quais 25 eram licenciados em Pedagogia, seis em Ciências Biológicas, três em Educação Física e um em História. Do total, apenas três professores possuíam cargos efetivos; os outros 32 contratados pela Prefeitura Municipal (CORUMBÁ, 2019b). Para lecionar nas Escolas das Águas, de acordo com informações da Equipe Gestora em 2019, os professores deveriam estar dispostos a residir nas dependências da própria unidade de ensino durante o período letivo. Isso porque, "raramente há registros de professores oriundos das comunidades ribeirinhas que atuam nas Escolas das Águas; geralmente vivem na cidade e se deslocam para as unidades de ensino para trabalhar e lá se alojarem durante o período de aulas" (NOZU; KASSAR, 2020, p. 9).

Diante dos desafios pessoais e profissionais a serem enfrentados pelos professores, a equipe gestora das Escolas das Águas usualmente mantém uma agenda de formação pedagógica, com realização na sede administrativa, antes do período letivo e nos interstícios dos bimestres - quando os docentes retornavam para o perímetro urbano por alguns dias (RDC-2020). 
http://dx.doi.org/10.5902/1984686X49204

Havia, em 2019, 30 profissionais técnico-administrativos - entre agentes de limpeza, agentes de cozinha, tratoristas/piloteiros e monitores de transportes, monitores de alojamentos - atuando em oito unidades de ensino, com contratos temporários firmados com a Prefeitura Municipal (CORUMBÁ, 2019b).

Uma unidade de parceria público-privada, com organização diferenciada, tinha quadro técnico-administrativo contratado pelo Instituto Acaia e desenvolvia formações docentes específicas: "o Acaia Pantanal prepara formações que vão ao encontro do trabalho do professor, com formação de conteúdo curricular e também formação para a execução de oficinas e projetos que são realizados na metodologia de trabalho da Escola Jatobazinho" (PR1-2020 desta unidade).

É nesse contexto que se inserem estudantes identificados com NEE...

\section{Acesso de alunos com NEE às Escolas das Águas: alguns trombolhos}

Os rios recebem, no seu percurso, pedaços de pau, folhas secas, penas de urubu

E demais trombolhos. Seria como o percurso de uma palavra antes de chegar ao poema. Manoel de Barros (2000, p. 21)

Os caminhos que nos levam ao Pantanal revelam-se em desafios inesperados. As famílias dos povos das águas vivem nesse bioma, onde as Escolas das Águas emergem como um possível-viável de encontros de saberes e de palavras. Crianças e adolescentes buscam, nessas escolas, acolhimentos de outras formas de conhecer. Os alunos com NEE as frequentam desde os anos $1970^{16}$, ainda que os relatos da Equipe Gestora, em 2019, informaram que a política de inclusão, como indutora de matrículas, seja recente.

Em Corumbá, dois documentos, um do ano 2000 e outro de 2003, foram publicados para estabelecer uma Política Municipal de Educação Especial. Logo em seguida, em 2004, foi implantado o Centro Multiprofissional de Apoio ao Desenvolvimento Infanto-Juvenil (CMADIJ), com o intuito de dar suporte à educação inclusiva em implantação na região. $A$ essa ação da gestão municipal, somou-se a criação da primeira SRM, em 2005, para oferecimento de AEE ao PAEE (KASSAR et al., 2018).

Atualmente, documentos político-normativos locais têm previsto o acesso de estudantes PAEE nas Escolas das Águas, como o Plano Municipal de Educação ${ }^{17}$ que indica, dentre as estratégias da Meta 4 - Educação Especial - a implantação de SRM e a formação continuada de professores para o AEE nas Escolas das Águas (CORUMBÁ, 
http://dx.doi.org/10.5902/1984686X49204

2015). A DE-2019 narrou que "a inclusão começou a acontecer primeiramente com os alunos que já eram da comunidade próxima à escola", acrescentando que "muitas mães diziam 'meu filho não tem nada', mas a gente percebia que tinha alguma coisa". Nesse diapasão, a DE-2019 esclareceu que a conscientização das comunidades pantaneiras sobre a escolarização de crianças e de adolescentes com NEE contou com a colaboração de profissionais da Assistência Social, em ações do Programa Povo das Águas.

As atividades nas Escolas das Águas eram orientadas por um Regimento Escolar (CORUMBÁ, 2017b) e um Projeto Político Pedagógico (CORUMBÁ, 2017a), com vinculação à Escola Municipal Rural de Educação Integral Polo Porto Esperança e Extensões, mas, conforme informação, da Equipe Gestora, em 2019, de aplicação a todas unidades de ensino. Ambos os documentos trazem seções próprias para a inclusão de alunos com NEE. O Regimento Escolar trata da questão no Capítulo II, intitulado Da Educação Inclusiva, com quatro artigos (CORUMBÁ, 2017b). Assim, reza o artigo 50:

\footnotetext{
Art. 50 - A Unidade Escolar oportunizará aos alunos com necessidades educacionais especiais a inclusão em sala comum, garantindo-lhes o acesso à educação escolar e o desenvolvimento de suas potencialidades, flexibilizando e adaptando o currículo, a metodologia de ensino, oferecendoIhes, ainda, recursos diferenciados e processo de avaliação adequado ao desenvolvimento desses alunos (CORUMBÁ, 2017b, p. 19).
}

Os artigos 51, 52 e 53 do Regimento Escolar abordam, respectivamente: a articulação da saúde e da educação para os atendimentos especializados; o AEE em ambiente domiciliar e hospitalar; e as parcerias com os serviços de apoio pedagógico especializado e outras instituições de ensino, para a construção da educação inclusiva (CORUMBÁ, 2017b).

Por sua vez, o Projeto Político Pedagógico (PPP) dispõe sobre o Atendimento aos Alunos com Necessidades Especiais no capítulo XVI, fundamentando-se nas Diretrizes Nacionais para a Educação Especial na Educação Básica (BRASIL, 2001). O PPP destaca que "a caracterização e classificação do aluno com necessidades especiais se fazem necessárias para definir a metodologia curricular e como consequência, o seu processo educativo" (CORUMBÁ, 2017a, p. 20).

Verificamos que, apesar de a Política Nacional de Educação Especial na Perspectiva da Educação Inclusiva (BRASIL, 2008) adotar o termo "Público-Alvo da Educação Especial", vários documentos municipais e escolares recentes utilizam a expressão "Necessidades Educacionais Especiais". Essas (des)construções textuais locais evidenciam, inclusive, o movimento complexo de manutenção, de incorporação e de 
http://dx.doi.org/10.5902/1984686X49204

atuação da política de inclusão no contexto da prática. Ressaltamos a compreensão da política de inclusão "em um processo, tão diverso e repetidamente contestado e/ou sujeito a diferentes 'interpretações' conforme é encenado (colocado em cena, em atuação) (ao invés de implementado) de maneiras originais e criativas dentro das instituições e das salas de aula" (BALL; MAGUIRE; BRAUN, 2016, p. 13).

A identificação das NEE dos alunos nas Escolas das Águas segue o padrão recomendado pela REME de Corumbá: deve-se partir da percepção inicial do professor sobre quaisquer características apresentadas pelo aluno. Uma coordenadora pedagógica e uma professora relataram como se efetiva tal procedimento:

Quando o professor, que é quem está lá, percebe, já comunica a coordenação: "olha o aluno está com dificuldade". E a gente sempre tem um questionário que vem do CMADIJ, então pede para o professor preenchê-lo. Essa ficha é encaminhada para o CMADIJ, que faz um diagnóstico e aí também, se é parte médica, entram os profissionais (CP2-2019).

Então, cheguei com a cara e a coragem, formada em Ciências Biológicas, e eu já fiquei sabendo que eu teria dois alunos especiais, mas eles não tinham laudos. O que acontece é que as professoras já tinham respondido vários questionários, tinham observado as características deles, da aprendizagem, e respondido alguns questionários. Só que como não tinha laudo eu não sabia do que se tratava e, como não tenho nenhuma especialização, também não tinha muita ideia. Mas, observando, tinha um que realmente apresentava um problema de aprendizagem e o outro, na minha opinião, assim, totalmente leiga, não, pois ele acompanhava bem todas as disciplinas. Mas um tinha lapsos de memória, tinha crises de risos, então eu não sabia identificar (PR12020 de Santa Mônica).

O questionário informativo indicado pela PR1-2020 de Santa Mônica e pela CP2-2019, a que tivemos acesso, continha campos para: a) os dados pessoais do aluno; b) as informações sobre o ano em que estava matriculado e se tinha histórico de retenção escolar; c) os motivos do encaminhamento - as principais dificuldades do aluno em sala de aula; d) os procedimentos pedagógicos usados com o aluno; e) o período em que o aluno foi observado; f) as interações entre família-escola-aluno; g) os anseios do professor para alcançar os objetivos pedagógicos; e h) a necessidade de adaptação do currículo e de acessibilidade na escola e na família (CORUMBÁ, 2019d).

Embora o questionário fosse preenchido pelo professor regente, no espaço das Escolas das Águas, a realização da avaliação especializada educacional e clínica, via de regra, requeria o deslocamento dos alunos e de seus familiares até o perímetro urbano de Corumbá, cujo custo do trajeto costuma ser elevado, sobretudo ao se atentar a renda familiar das comunidades das águas (CRUZ, 2018). Diante desse impasse, uma das coordenadoras pedagógicas assim se manifestou: 
http://dx.doi.org/10.5902/1984686X49204

Por questão de logística o nosso trabalho fica bastante comprometido. Nós até realizamos o trâmite inicial, que é o professor preencher o relatório informativo, fazer a anamnese, mandar para a Secretaria de Educação, que tem um núcleo responsável multifuncional [CMADIJ]. Contudo, esse núcleo não tem muitos profissionais para atender uma rede, com cerca de 50 unidades escolares, entre Ensino Fundamental e Educação Infantil. Então, no nosso caso específico, não conseguimos deslocar esse profissional para que ele vá até a escola - para que ele faça todo o trabalho de observação da criança em sala e também com a família. Foram raras as vezes, muito raras mesmo, que nós conseguimos mandar profissionais para fazer esse trabalho nas Escolas das Águas (CP1-2019).

Da mesma maneira, o alcance do diagnóstico clínico é constantemente permeado por barreiras relacionadas ao acesso à saúde nas regiões das águas (ECOA, 2010; ZERLOTTI, 2014; CRUZ, 2018). Em outros contextos rurais brasileiros, também foram identificados percalços para avalições clínicas de estudantes camponeses com suspeitas de NEE (NOZU; SÁ; DAMASCENO, 2019). Os serviços médicos oportunizados pelo Programa Povo das Águas concentram-se no atendimento de clínicos gerais. Conforme a CP2-2019, "quando há a necessidade de um diagnóstico mais preciso é feito um encaminhamento para um médico especialista em Corumbá [área urbana]". Uma professora da unidade de Santa Mônica explicou:

Essa questão da distância, para atendimentos na cidade, às vezes a gente até entende o lado dos pais, porque como eles são empregados tudo depende muito do patrão. O tempo para chegar até a cidade é três dias de barco, mais o [tempo de locomoção com o] trator. Então depende do patrão liberar para vir para a cidade, e aí mesmo liberando o pai não tem a informação de onde recorrer, como recorrer. Às vezes acha que vai ter um custo, que vai ter que pagar, ou que demora muito. Então, fica difícil para eles saírem de lá, porque geralmente o pai trabalha na fazenda e a mãe é cozinheira ou cuida da casa, e aí tanto o pai quanto a mãe saindo de lá, já gera um custo para o patrão. Tem patrões e patrões: uns liberam, outros não (PR2-2020 de Santa Mônica).

Outrossim, há casos em que os alunos já foram matriculados nas Escolas das Águas com a apresentação de diagnóstico clínico. Particularmente, um aluno de Santa Aurélia, antes de ser matriculado na unidade, já havia frequentado, por cerca de três anos, uma instituição especializada no perímetro urbano de Corumbá, segundo a CP2-2019.

Por meio de interlocuções com os professores e a equipe gestora das Escolas das Águas, levantamos informações - apresentadas no Quadro 1 - sobre os alunos considerados com NEE, englobando os definidos como PAEE, matriculados no ano de 2019. 
http://dx.doi.org/10.5902/1984686X49204

Quadro 1 - Alunos identificados com Necessidades Educacionais Especiais nas Escolas das Águas (2019)

\begin{tabular}{|c|c|c|}
\hline UNIDADE & ALUNOS / NEE & ANO ESCOLAR \\
\hline \multirow[t]{2}{*}{ Porto Esperança } & Pedro / deficiência física (com laudo clínico) & 9ano - EF \\
\hline & Patrícia / baixa visão (com laudo clínico) & 60 ano $-E F$ \\
\hline Santa Aurélia & Fabrício / TEA (com laudo clínico) & 3ㅇ ano - EF \\
\hline São João & Gabriela / "síndrome" (sem laudo clínico) & Pré I-El \\
\hline Sebastião Rolon & Sem registros & - \\
\hline Nazaré & Juliana / deficiência física (com laudo clínico) & $8^{\circ}$ ano $-E F$ \\
\hline Paraguai Mirim & Henrique / "dislexia" (sem laudo clínico) & $3^{\circ}$ ano $-\mathrm{EF}$ \\
\hline Jatobazinho & Fernanda / deficiência intelectual (com laudo clínico) & $5^{\circ}$ ano $-\mathrm{EF}$ \\
\hline \multirow[t]{2}{*}{ São Lourenço } & João / "ausência de verbalização" (com laudo clínico) & $5^{\circ}$ ano $-\mathrm{EF}$ \\
\hline & Lucas / "problema comportamental" (sem laudo clínico) & $2^{\circ}$ ano $-E F$ \\
\hline \multirow[t]{2}{*}{ Santa Mônica } & Victor / "dificuldade de aprendizagem" (sem laudo clínico) & $5^{\circ}$ ano $-E F$ \\
\hline & Isaías / "problemas fisiológicos" (sem laudo clínico) & $5^{\circ}$ ano $-\mathrm{EF}$ \\
\hline
\end{tabular}

Fonte: Elaborado pelos autores a partir de dados da pesquisa (2019).

Legenda: TEA - Transtorno do Espectro Autista; El - Educação Infantil; Ensino Fundamental - EF.

As dificuldades de acesso à possibilidade de atendimento para um possível diagnóstico estão evidentes no Quadro 1. Quase $50 \%$ dos alunos não possuem laudo clínico ou parecer educacional especializado para considerá-los ou não PAEE. Os 11 alunos registrados com NEE representam cerca de 3,75\% das 293 matrículas nas Escolas das Águas em 2019, porcentagem maior que a encontrada por Silva Filho (2017) na região urbana, em 2015, quando a REME possuía 9.664 matrículas, das quais 171 de alunos PAEE $(1,77 \%)^{18}$.

\section{Permanência de alunos com NEE nas Escolas das Águas: propósitos e despropósitos}

O menino era ligado em despropósitos. Quis montar os alicerces de uma casa sobre orvalhos. Manoel de Barros (1999, s/p).

Em qualquer parte, podemos encontrar crianças que parecem ser "ligadas em despropósitos", como se a lógica esperada pela escola não fosse por elas compartilhada... A essas crianças, costumam ser atribuídas identificações que as diferenciam do 'geral' dos alunos e, então, passam a fazer parte do grupo de alunos com NEE e, após um 'laudo', do PAEE. Elas têm acessado as Escolas das Águas. Mas quais estratégias educacionais têm sido adotadas pelos profissionais para possibilitar a sua permanência nessas localidades?

As narrativas dos gestores e professores evidenciaram uma multiplicidade de concepções e de práticas relacionadas à permanência dos alunos com NEE nas Escolas 
http://dx.doi.org/10.5902/1984686X49204

das Águas. Tais como os rios do Pantanal, essas narrativas ora se encontravam, ora criavam caminhos próprios.

De forma uníssona, os agentes do contexto da prática avaliaram positivamente a participação e a interação dos alunos com NEE nas unidades de ensino. Alguns enunciados elucidaram tal análise: "os alunos com necessidades especiais acompanham, estão inseridos nas brincadeiras, nas atividades a serem desenvolvidas. Eles nunca estão fora, estão sempre incluídos" (CP2-2019); "ela [Fernanda] se coloca muito bem, tem uma autonomia muito grande, uma participação muito grande nas atividades e tem se desenvolvido muito, principalmente na relação social com as pessoas" (PR1-2020 de Jatobazinho); "na disciplina de Educação Física, ele [Fabrício] pede para estar junto com as crianças. Então, assim, ele tem mais facilidade por estar brincando" (PR1-2019 de Santa Aurélia).

No que diz respeito às práticas pedagógicas, houve relatos que transitaram entre atividades comuns, adaptadas e paralelas no cotidiano da sala de aula. De acordo com Capellini e Zerbato (2019), as primeiras, também chamadas de acessíveis, possibilitam a participação de todos os alunos; as segundas, embora abordem o mesmo conteúdo, realizam adaptações de acordo com as especificidades dos alunos; e, por fim, as do terceiro tipo "destoam daquilo que é realizado pelos demais estudantes da turma, justificando a necessidade de sua realização, pela suposta incapacidade do estudante-alvo" (CAPELLINI; ZERBATO, 2019, p. 27). Algumas falas trouxeram indícios dessa variabilidade de práticas:

Eu, por exemplo, não tenho uma metodologia para ele [João]. Eu trabalho geral até para incluí-lo nas atividades, tanto é que ele gosta de participar (PR1-2020 de São Lourenço).

A gente faz um trabalho muito inclusivo para ela [Fernanda], com atividades com as outras crianças, respeitando o seu limite intelectual e o seu desenvolvimento. Então, assim, o trabalho desenvolvido é geral, colocandoa no meio dos alunos, mas, ao mesmo tempo, sendo mais específico nesse acompanhamento do desenvolvimento dela. Ela é vista como qualquer uma criança da escola, a gente não faz distinção em nenhum tipo de trabalho. Então, ela participa ativamente de todos os momentos (PR1-2020 de Jatobazinho).

Ela [Patrícia] precisa de ampliação. Então, nós temos que estar fazendo uma adaptação. Âs vezes, nós levamos uma fotocópia ampliada e procuramos deixá-la em um local onde possa ter acesso ao quadro, de forma que não vá prejudicá-la tanto (PR1-2019 de Porto Esperança).

Nós fazemos atividades complementares com ele [Henrique], porque ele não consegue acompanhar o currículo a seguir. Então a gente foi adaptando algumas atividades e, ao mesmo tempo, não deixando que ele ficasse separado da turma, porque são salas multisseriadas (PR1-2020 de Paraguai Mirim). 
http://dx.doi.org/10.5902/1984686X49204

Olha, de vez em quando a gente dá algumas atividades diversificadas, porque ele [João] está muito atrasado para a idade. Ele está na quinta, mas a gente passa da segunda, da primeira, da terceira para ver se ele consegue acompanhar os colegas (PR2-2020 de São Lourenço).

O trabalho em grupo e o uso da ludicidade também compuseram o quadro narrativo das práticas pedagógicas voltadas à inclusão dos alunos com NEE: "procuro sempre dividir os alunos em dupla. Isso faz com que ela [Juliana], que é mais tímida, se solte mais" (PR12019 de Nazaré); "eu sempre a insiro [Gabriela] com um outro aluno. E outra coisa também que desperta muito o interesse dela é a brincadeira. Então você tem que preparar uma aula lúdica, que é para ela poder se entrosar" (PR1-2019 de São João). A utilização de recurso visual associada ao cotidiano sociocultural de um aluno com Transtorno do Espectro Autista (TEA) foi descrita por um professor:

A disciplina que eu fiquei encarregado de ministrar é Inglês. Eu tento fazer com que ele [Fabrício] associe a imagem com o que eu falo, a imagem com o que ele vê também. Por exemplo, eu consegui que visualizasse o cavalo na hora que eu estava falando horse e ele percebeu que era o cavalo, porque é um tipo de locomoção que eles utilizam (PR2-2019 de Santa Aurélia).

A atuação em turmas multisseriadas e sua relação com a inclusão de alunos com NEE também foi apreendida por diferentes olhares. Ora era elemento que amplificava os desafios da inclusão: "é uma loucura, mas a gente tenta incluir. Até estava pensando nisso... multissérie já é uma loucura, ainda mais com a inclusão" (PR2-2019 de Porto Esperança); "para incluir nas turmas multisseriadas a gente tem que ser um pouco ninja, homem aranha, tecer as teias para poder trabalhar, porque, olha, não é fácil!" (PR2-2019 de Nazaré). Ora como trabalho caracterizado "por ser uma ação educativa com a diversidade" (OLIVEIRA, 2016, p. 333), tal qual nos informou a PR3-2019 de Porto Esperança: "como a gente atende várias crianças e vários níveis, não sente que está atendendo uma criança de uma forma específica. Para nós, que atendemos o multisseriado, passamos por cima disso aí, porque já atendemos várias crianças de uma forma diferente".

Diante dos enunciados dos professores, sob o viés da Teoria da Atuação, salientamos que "a escola não é nem uma entidade simples nem coerente. [...]. As escolas não são uma peça só. Elas são redes precárias de grupos diferentes e sobrepostos de pessoas, de artefatos e de práticas" (BALL; MAGUIRE; BRAUN, 2016, p. 201). Assim, os professores das Escolas das Águas encenam suas práticas de maneiras diversas, tal qual um processo de bricolagem, a partir da justaposição de suas concepções, princípios e materialidades. 
http://dx.doi.org/10.5902/1984686X49204

O vulto da incapacidade dos estudantes com NEE, ancorado na visão clínicoterapêutica (OLIVEIRA, 2016), também teve ressonância em alguns dizeres dos professores, nutrindo, inclusive, o direcionamento desses educandos para instituições especializadas. A fala de uma professora da unidade de São João, que atuou anteriormente com o aluno com TEA, matriculado em 2019 na unidade de Santa Aurélia, foi exemplificativa: "para ele [Fabrício] tem que ser trabalhada a coordenação motora fina, trabalhar o básico com ele. Porque mais do que isso, a gente não vai conseguir dele, a não ser que ele vá para, por exemplo, a APAE. Ele pode ir para lá e conseguir coisa mais elevada" (PR1-2019 de São João).

A Educação Especial, como AEE, estava disponibilizada apenas na unidade de Santa Aurélia, por meio da contratação de uma professora de apoio para atuar junto ao aluno com TEA, no ano de 2019. Foi o primeiro atendimento de Educação Especial alocado nas Escolas das Águas. Essa ação foi destacada, pela Equipe Gestora (2019) e pelos professores da unidade de ensino, como um grande avanço para a promoção da inclusão escolar. As palavras de uma professora foram representativas: "foi uma grande vitória contar com a professora de apoio, porque a secretaria vem lutando há tempos para isso acontecer. Eu creio que ela é fundamental, por ser uma sala multisseriada e por ter de lidar com vários planejamentos e várias coisas diferentes" (PR1-2019 de Santa Aurélia).

A professora de apoio, PE-2019, ao narrar o seu trabalho especializado, indicou a observação das interações do aluno com TEA ("vi a convivência dele com os pais, com os alunos, com os professores"), o contato com os materiais escolares ("comecei a apresentar um caderno, um livro, para ele manusear"), a confecção de materiais pedagógicos ("eu inventei alguns brinquedos, adaptei alguns materiais e recursos"), a realização de atividades verbais ("ele não falava nada, só balbuciava algumas palavras; agora ele já consegue falar 'abrir' e 'fechar', 'sim' ou 'não'”) e relacionadas à autonomia. Entretanto, a PE-2019 compartilhou alguns entraves à sua atuação, "principalmente a falta de materiais" e de "um planejamento preparado especificamente para o aluno". De acordo com os professores da unidade de Santa Aurélia, não havia um momento de planejamento conjunto destinado à análise das especificidades do aluno com TEA. Esse dado, por um lado, amplifica o eco de pesquisas em contextos educacionais ribeirinhos, indígenas e camponeses, cujos resultados evidenciam a ausência, o improviso e a assistematicidade de articulação entre o ensino comum e o especializado (FERNANDES, 2015; COSTA FILHO, 2016; NOZU, 2017; NOZU; SÁ; DAMASCENO, 2019). Por outro, faz ver sua 
http://dx.doi.org/10.5902/1984686X49204

proximidade com o contexto urbano em que esses problemas também ocorrem (MATOS; MENDES, 2015). Em levantamento realizado em 2015, Silva Filho (2017) constatou que, com quase 50 unidades escolares, a REME de Corumbá havia instalado apenas oito SRM, sendo seis em região urbana e duas em escolas localizadas em assentamentos rurais.

As demandas por ações da Educação Especial para potencialização da inclusão nas Escolas das Águas foram recorrentes nos enunciados dos professores: "o que falta é mais investimento, mais investimento nas escolas, mais salas adequadas, ter salas de AEE. Têm em escolas da cidade e nas Escolas das Águas não têm? Precisa de salas dessas! Seria um bom auxílio" (PR2-2019 de São João); "é preciso, pelo menos uma vez por mês, uma especialista ir até lá e conversar conosco e com os pais, pelo menos tentar. Até para dar orientação para eles! Nós não podemos falar porque não somos dessa área [Educação Especial], não somos especialistas" (PR1-2020 de São Lourenço).

A principal dificuldade apontada, em 2019, pela Equipe Gestora para uma assessoria periódica do CMADJI junto às Escolas das Águas, foi o difícil deslocamento até as comunidades ribeirinhas e pantaneiras. Como explanou a CP3-2019: "o desafio é conseguir um profissional que vá para lá. E as dificuldades vão desde a logística, porque vai precisar de transporte e alojamento, até o professor ter o perfil de ir para a Escola das Águas e permanecer por lá para fazer o atendimento desses alunos". Embora tenha concordado que “a principal dificuldade é a logística”, a CP1-2019 salientou:

O profissional tem que ter essa consciência que ele tem que ir no meio do Pantanal, porque a Rede Municipal de Ensino de Corumbá tem escola no meio do Pantanal. Então não tem isso, achar que vai trabalhar sobre inclusão e ficar só aqui na cidade, não tem! Você vai ter que pegar barquinho, pegar trator, pegar cavalo, não tem jeito. Então eu penso que esses são os maiores embates.

Em que pese a relevância do AEE, o modelo de SRM tem se mostrado insuficiente e inadequado para as realidades de muitas escolas localizadas no meio rural, principalmente pela exigência dos atendimentos no contra turno das aulas, bem como pela organização e pelo transporte escolar (NOZU, 2017; NOZU; SÁ; DAMASCENO, 2019).

Outro grande desafio diz respeito à formação e ao regime temporário de trabalho dos professores. Dos 35 docentes, apenas três eram efetivos: "os nossos professores não têm a formação para trabalhar com esses alunos [com NEE]. Além disso, sempre acaba mudando de professor e começando esse processo todo de novo, afetando o objetivo, que é o aluno" (CP3-2019); "o desafio é encontrar profissionais, pois a rotatividade é muito 
http://dx.doi.org/10.5902/1984686X49204

grande. É preciso que eles sejam capazes de entender o funcionamento da escola e de como aplicar isso com crianças com necessidades especiais" (PR1-2020 de Jatobazinho).

\title{
Convidando a desver palavras desabertas
}

\author{
Eu bem sabia que a nossa visão é um ato poético do olhar. \\ Assim aquele dia eu vi a tarde desaberta nas margens do rio. \\ Como um pássaro desaberto em cima de uma pedra na beira do rio. \\ Depois eu quisera também que a minha palavra fosse desaberta na \\ margem do rio. \\ Manoel de Barros (2015, p. 69).
}

As Escolas das Águas caracterizam-se pela diversidade de sujeitos, de tempos e de espaços educativos: alunos com múltiplas identidades socioculturais vivendo no Pantanal; variados calendários escolares adaptados às particularidades ambientais locais; diferentes regimes de funcionamento (regular ou integral; externato ou internato semanal/bimestral) e formas de enturmação.

As políticas de educação inclusiva têm produzido efeitos, de diferentes modos, no acesso e na permanência de alunos nas Escolas das Águas. Na tentativa de "desver" esse lócus, "para sair daquele lugar imensamente e sem lado", podemos tentar compreendê-lo com os olhos do "menino que carregava água na peneira" e descobrir que os desacertos podem encobrir encantamentos, como nos estimula Manoel de Barros (1999; 2015): na lida do acesso à escola com sua riqueza de imagens, cheiros, balanços, sons... e na diversidade da permanência, na mistura de culturas, de idades, de gestos, de histórias, de conversas, de possibilidades.

A pluralidade de histórias, valores, experiências e formações também constitui os profissionais das Escolas das Águas, influenciando os movimentos para a atuação no processo de inclusão dos alunos com NEE em cada unidade de ensino. Isso porque o contexto da prática compreende um 'microprocesso político', no qual os atores concretos não apenas executam uma política macro, mas a recriam e a recontextualizam a partir de suas condições objetivas e subjetivas (MAINARDES, 2006; BALL; MAGUIRE; BRAUN, 2016). Nessa 'recriação', professores e gestores desenvolvem suas práxis dentro de circunstâncias bastante peculiares. Nesse processo, identificamos vozes de um olhar preso a limites, como a crença de que as características de alguns alunos seriam mais bem acolhidas por instituições especializadas de Educação Especial, mas também que evidenciam novos e melhores horizontes, como a criação de materiais e brinquedos e a 
elaboração de atividades para que todos os alunos se apropriem de todas as possibilidades escolares.

Para a 'recriação' mais promissora, talvez sejam necessárias mudanças de olhares e percepções, em que os aparentes limites fisiográficos passem a ser convites a possibilidades ainda não construídas. Na Educação Especial, já percebemos que tomar a criança/o adolescente pela falta (de linguagem, de comportamento, de inteligência, de visão etc.) nos conduziu a processos educativos restritivos e inadequados. Trabalhos que passaram a apreender as características dessas crianças como indícios/possibilidades de desenvolvimento (CARVALHO, 2006; DAINEZ; SMOLKA, 2014; SCHMIDT, 2012) têm sido mais promissores e nos levado a ultrapassar limites aparentemente intransponíveis. Esse olhar também pode se fazer presente no contexto da Escolas das Águas.

Entendemos que é preciso construir alternativas de escolaridade e de oferta de AEE a partir das realidades, das culturas, dos saberes e das vivências das populações que habitam e produzem sua existência no contexto pantaneiro. Como exemplo, particularmente no âmbito das Escolas das Águas, é relevante pensar inúmeras possibilidades para a realização de AEE, com ou sem SRM, sobretudo pelo fato de que a maioria das unidades funcionar em tempo integral, além das peculiaridades socioculturais, dos transportes e dos deslocamentos no Pantanal. A literatura produzida sobre a disponibilização de Educação Especial em regiões rurais tem sinalizado que o modelo de AEE em SRM, como proposto nos documentos da política de educação inclusiva no Brasil, não satisfaz as necessidades e as realidades das populações do campo, das florestas e das águas (OLIVEIRA, 2016; NOZU, 2017; NOZU; SÁ; DAMASCENO, 2019).

Sob a perspectiva elaborada por Ball e colaboradores, nos anos 1990, conhecida como Policy Cycle Approach, nas análises das políticas educacionais devem ser levados em conta os diferentes contextos de um 'ciclo', que são inter-relacionados, sem dimensão temporal e que não se constituem em sequências fixas ou etapas lineares (MAINARDES, 2006). Há o contexto de influência, quando, geralmente, "políticas públicas são iniciadas e os discursos políticos são construídos" (MAINARDES, 2006, p. 51), entre disputas, embates em processos complexos de articulações e pressões internas e externas. Nessa movimentação, identificamos influências internacionais no processo de formulação de políticas nacionais (MAINARDES, 2006; BALL, 2007). O documento produzido na Conferência Mundial Sobre Necessidades Educativas Especiais, organizada pela 
http://dx.doi.org/10.5902/1984686X49204

UNESCO, na Espanha, em 1994, pode ser identificado como um dos documentos indutores da política educacional brasileira.

Se considerada a Declaração de Salamanca para a garantia da escolarização obrigatória das populações enfatizadas como historicamente marginalizadas, vemos que contém marcas da ótica do custo-benefício ou relación costo-eficacia (UNESCO, 1994). No Brasil, tais discursos foram apropriados, adequados e reconfigurados em contexto de ajustamento fiscal e reformas econômicas orientadas para o mercado (BRASIL, 1995), sob um Plano Diretor da Reforma do Aparelho do Estado, com a adoção de uma administração gerencial e evocação de preceitos de governança, sob uma perspectiva de 'enxugamento' da 'máquina estatal', que se fizeram presentes nas políticas federais, estaduais e municipais, mesmo com alterações dos governos. A 'leitura' brasileira do documento mantém a diretriz econômica do custo-benefício do documento original. No contexto específico, tal diretriz se materializa no pequeno número de profissionais do CMADIJ, nos poucos professores efetivos e no restrito investimento em salas e demais espaços adequados.

Dessa forma, se, atualmente, a diversidade da população brasileira acende às escolas, como os alunos das Escolas das Águas, as condições infraestruturais marcam limites do pleno gozo do direito à educação. Portanto, esclarecemos que o convite ao "desver" e ao encantamento não pode significar - de forma alguma - a conformidade com os limites das políticas públicas sociais e com as precariedades das condições de vida dos povos das águas.

\section{Referências}

ABREU, Cleide Marcelina Marçal. A implantação das escolas ribeirinhas no Pantanal corumbaense: um elemento de enfrentamento ao trabalho infantil. 2018. Dissertação (Mestrado em Educação) - Universidade Federal de Mato Grosso do Sul, Corumbá, 2018.

AGÊNCIA NACIONAL DAS ÁGUAS et al. Programa de ações estratégicas para o gerenciamento integrado do Pantanal e da Bacia do Alto Paraguai: relatório final. Brasília: TDA Desenho \& Arte Ltda., 2004.

APA. Manual Diagnóstico e Estatístico de Transtornos Mentais: DSM-5. 5. ed. Porto Alegre: Artmed, 2015.

BALL, Stephen J. Big policies/small world: an introduction to international perspectives in education policy. In: LINGARD, Bob; OZGA, Jenny. The RoutledgebFalmer Reader in Education Policy and Politics. London: Routledge, 2007. p. 36-47. 
BALL, Stephen J.; MAGUIRE, Meg; BRAUN, Annette. Como as escolas fazem as políticas: atuação em escolas secundárias. Ponta Grossa: Editora UEPG, 2016.

BARROS, Manoel. O menino que carregava água na peneira. In: BARROS, Manoel. Exercícios de ser criança. Bordados de Antônia Zulma Diniz, Ângela, Marilu, Martha e Sávia Dumont sobre desenhos de Demóstenes. Rio de Janeiro: Salamandra, 1999.

BARROS, Manoel. Ensaios fotográficos. Rio de Janeiro: Editora Record, 2000.

BARROS, Manoel. Menino do mato. Rio de Janeiro: Objetiva, 2015.

BARROS, Manoel. Livro sobre nada. Rio de Janeiro: Alfaguara, 2016.

BARROS, Manoel. O guardador de águas. Rio de Janeiro: Alfaguara, 2017.

BOWE, Richard; BALL, Stephen J.; GOLD, Anne. Reforming education \& changing schools: case studies in policy sociology. London: Routledge, 1992.

BRASIL. Política Nacional de Educação Especial. Brasília: MEC/SEESP, 1994.

BRASIL. Plano Diretor da Reforma do Aparelho do Estado. Brasília: Ministério da Administração Federal e Reforma do Estado, 1995.

BRASIL. Lei n. 9.394, de 20 de dezembro de 1996. Estabelece as Diretrizes e Bases da Educação Nacional. Disponível em: http://www.planalto.gov.br/ccivil_03/leis/19394.htm. Acesso em: 9 ago. 2020.

BRASIL. Resolução CNE/CEB n. 2, de 11 de setembro de 2001. Institui Diretrizes Nacionais da Educação Especial na Educação Básica. Brasília: MEC/CNE, 2001.

\section{BRASIL. Política Nacional de Educação Especial na Perspectiva da Educação Inclusiva} Brasília: MEC/SECADI, 2008. Disponível em:

http://portal.mec.gov.br/index.php?option=com_docman\&view=download\&alias=16690politica-nacional-de-educacao-especial-na-perspectiva-da-educacao-inclusiva05122014\&Itemid=30192. Acesso em: 30 jun. 2020.

BRASIL. Resolução CNE/CEB n. 4, de 2 de outubro de 2009. Institui Diretrizes Operacionais para o Atendimento Educacional Especializado na Educação Básica, modalidade Educação Especial. Brasília: MEC/CNE, 2009.

BRASIL. Decreto n. 7.611 de 17 de novembro de 2011. Dispõe sobre a educação especial e o atendimento educacional especializado e dá outras providências. Disponível em: http://www.planalto.gov.br/ccivil_03/_ato2011-2014/2011/decreto/d7611.htm. Acesso em: 9 ago. 2020.

BUENO, José Geraldo Silveira. As políticas de inclusão escolar: uma prerrogativa da educação especial? In: BUENO, José Geraldo Silveira; MENDES, Geovana Mendonça Lunardi; SANTOS, Roseli Albino dos (Org.). Deficiência e escolarização: novas perspectivas de análise. Araraquara: Junqueira\&Marin; Brasília: CAPES, 2008. p.43-63. 
CAPELLINI, Vera L. Messias Fialho; ZERBATO, Ana Paula. O que é ensino colaborativo? São Paulo: Edicon, 2019.

CARVALHO, Maria de Fátima. Conhecimento e vida na escola: convivendo com as diferenças. Campinas, SP: Autores Associados; ljuí, RS: UNIJUI, 2006.

CORUMBÁ. Lei № 2.263, de 24 de agosto de 2012. Cria o Programa Povo das Águas, de atendimento às comunidades situadas nas regiões das águas do município de Corumbá. Diário Oficial de Corumbá: Corumbá, MS, ano 1, n. 44, p. 1-2, 27 ago. 2012.

CORUMBÁ. Plano Municipal de Educação 2015-2025. Corumbá, MS: Secretaria Municipal de Educação, 2015.

CORUMBÁ. Secretaria Municipal de Educação. Escola Municipal Rural de Educação Integral Polo Porto Esperança e Extensões. Projeto Político Pedagógico. Corumbá: SEMED, 2017a.

CORUMBÁ. Secretaria Municipal de Educação. Escola Municipal Rural de Educação Integral Polo Porto Esperança e Extensões. Regimento Escolar. Corumbá: SEMED, 2017b.

CORUMBÁ. Secretaria Municipal de Educação. Movimentação de matrículas de 2009 a 2019 das Escolas das Águas. Corumbá: Secretaria das Escolas das Águas, 2019a. (Mimeo).

CORUMBÁ. Secretaria Municipal de Educação. Pasta de informações do ano corrente. Corumbá: Secretaria das Escolas das Águas, 2019b. (Mimeo).

CORUMBÁ. Secretaria Municipal de Educação. Matrículas para o ano letivo de 2019: 17/09/2019 - todas as escolas. Corumbá: Secretaria das Escolas das Águas, 2019c. (Mimeo).

CORUMBÁ. Secretaria Municipal de Educação. Questionário informativo. Corumbá: CMADJI, 2019d. (Mimeo).

COSTA FILHO, Waldir Macieira da. O desafio da educação inclusiva para crianças com deficiência intelectual: um estudo de caso da Escola Estadual Marta da Conceição em Belém-Pará-Amazônia. 2016. Dissertação (Mestrado em Direitos Humanos e Cidadania) Universidade de Brasília, Brasília, 2016.

CRUZ, Mirian Bastos de Oliveira da. A ciranda dos jogos e brincadeiras nas falas das crianças ribeirinhas. 2018. Dissertação (Mestrado em Educação) - Universidade Federal de Mato Grosso do Sul, Corumbá, 2018.

DAINEZ, Débora: SMOLKA, Ana Luiza Bustamante. O conceito de compensação no diálogo de Vigotski com Adler: desenvolvimento humano, educação e deficiência. Educação e Pesquisa, São Paulo, v. 40, n. 4, p. 1093-1108, out.-dez. 2014.

ECOA. Diagnóstico das comunidades das águas: Porto Manga, Baía do Castelo, Paraguai-Mirim e Barra do São Lourenço. Campo Grande: ECOA, 2010. 
http://dx.doi.org/10.5902/1984686X49204

ESTEBAN, Maria Paz Sandín. Pesquisa qualitativa em educação: fundamentos e tradições. Porto Alegre: AMGH, 2010.

FERNANDES, Ana Paula Cunha dos Santos. A escolarização da pessoa com deficiência nas comunidades ribeirinhas da Amazônia Paraense. 2015. Tese (Doutorado em Educação Especial) - Universidade Federal de São Carlos, São Carlos, 2015.

GARCIA, Rosalba Maria Cardoso. Políticas inclusivas na educação: do global ao local. In: BAPTISTA, Claudio Roberto; CAIADO, Katia Regina Moreno; JESUS, Denise Meyrelles (Org.). Educação especial: diálogo e pluralidade. Porto Alegre: Mediação, 2010. p. 11-23.

GLAT, Rosana; BLANCO, Leila de Macedo Varela. Educação Especial no contexto de uma Educação Inclusiva. In: GLAT, Rosana (Org.). Educação inclusiva: cultura e cotidiano escolar. Rio de Janeiro: \&Letras, 2009. p. 15-35.

GONÇALVES, Karoline Batista. Pantanal transfronteiriço (Bolívia-Brasil-Paraguai) e as áreas protegidas: da produção de territórios as iniciativas de conservação. 2019. Tese (Doutorado em Geografia) - Universidade Federal da Grande Dourados, Dourados, 2019.

HAGE, Salomão Mufarrej; REIS, Maria Izabel Alves. Tempos, espaço e conhecimento nas escolas rurais (multi)seriadas e transgressão ao modelo seriado de ensino. Em Aberto, v. 31, n. 101, p. 77-91, ja.-abr. 2018. Disponível em:

http://rbep.inep.gov.br/ojs3/index.php/emaberto/article/view/3230. Acesso em: 15 maio 2020.

IBGE. Cidades e estados. Corumbá. 2019. Disponível em: https://www.ibge.gov.br/cidadese-estados/ms/corumba.html. Acesso em: 12 dez. 2019.

KASSAR, Mônica de Carvalho Magalhães. Percursos da constituição de uma política brasileira de educação especial inclusiva. Revista Brasileira de Educação Especial, Marília, v. 17, p. 41-58, maio-ago. 2011. Disponível em: https://www.scielo.br/scielo.php?pid=S141365382011000400005\&script=sci_abstract\&tlng=pt. Acesso em: 10 mar. 2020.

KASSAR, Mônica de Carvalho Magalhães et al. Educação especial na perspectiva da educação inclusiva em um município de Mato Grosso do Sul. Cadernos Cedes, Campinas, v. 38, n. 106, p. 299-313, set.-dez. 2018. Disponível em:

https://www.scielo.br/scielo.php?pid=S0101-32622018000300299\&script=sci_arttext. Acesso em: 15 jul. 2020.

MAINARDES, Jefferson. Abordagem do ciclo de políticas: uma contribuição para a análise de políticas educacionais. Educação e Sociedade, Campinas, v. 27, n. 94, p. 47-69, jan.-abr. 2006. Disponível em: https://www.scielo.br/pdf/es/v27n94/a03v27n94.pdf. Acesso em: 15 jul. 2020.

MATOS, Selma Norberto; MENDES, Enicéia Gonçalves. Demandas de professores decorrentes da inclusão escolar. Revista Brasileira de Educação Especial, Marília, v. 21, n. 1, p. 9-22, mar. 2015. Disponível em:

http://www.scielo.br/scielo.php?script=sci_arttext\&pid=S1413-

65382015000100009\&lng=en\&nrm=iso. Acesso em: 27 jul. 2020. 
MELO, Rogério Zaim de. Jogar e brincar de crianças pantaneiras: um estudo em uma "escola das águas". 2017. Tese (Doutorado em Educação) - Pontifícia Universidade Católica do Rio de Janeiro, Rio de Janeiro, 2017.

MENDES, Enicéia Gonçalves; CABRAL, Leonardo Santos Amâncio. Implicações da atual política de inclusão escolar no Brasil: mapeando desafios e possibilidades para o século XXI. Revista de Educação Especial e Reabilitação, Lisboa, v. 21, p. 41-53, 2014.

NOZU, Washington Cesar Shoiti. Educação especial e educação do campo: entre porteiras marginais e fronteiras culturais. 2017. Tese (Doutorado em Educação) Universidade Federal da Grande Dourados, Dourados, 2017.

NOZU, Washington Cesar Shoiti; KASSAR, Mônica de Carvalho Magalhães. Escolarização de crianças e adolescentes pantaneiros em tempos de COVID-19. Práxis Educativa, Ponta Grossa, v. 15, p. 1-20, 2020. Disponível em: https://www.revistas2.uepg.br/index.php/praxiseducativa/article/view/16193. Acesso em: 20 jul. 2020.

NOZU, Washington Cesar Shoiti; SÁ, Michele Aparecida de; DAMASCENO, Allan Rocha. Educação especial em escolas do campo e indígenas: configurações em microcontextos brasileiros. Revista Trabalho, Política e Sociedade, v. 4, n. 7, p. 51-64, jul.dez. 2019. Disponível em: http://costalima.ufrrj.br/index.php/RTPS/article/view/256. Acesso em: 10 maio 2020.

OLIVEIRA, Francisca Renata. Os nexos da educação integral no Pantanal de Corumbá-MS: práticas de ensino na escola Jatobazinho. 2018. Dissertação (Mestrado em Educação) - Universidade Federal de Mato Grosso do Sul, Corumbá, 2018.

OLIVEIRA, Ivanilde Apoluceno de. Desafios da educação inclusiva em escolas do campo na Amazônia paraense. In: MENDES, Enicéia Gonçalves; ALMEIDA, Maria Amélia (Org.). Inclusão escolar e educação especial no Brasil: entre o instituído e o instituinte. Marília: ABPEE, 2016. p. 329-341.

PAVEZI, Marilza; MAINARDES, Jefferson. Políticas de educação especial no estado de Alagoas. Revista Brasileira de Educação Especial, Bauru, v. 25, n. 4, p. 747-764, out.dez. 2019. Disponível em: https://www.scielo.br/scielo.php?pid=S141365382019000400747\&script=sci_arttext. Acesso em: 10 jun. 2020.

PRIETO, Rosângela Gavioli. Educação especial em municípios paulistas: histórias singulares ou tendências unificadoras? In: BAPTISTA, Claudio Roberto; JESUS, Denise Meyrelles de (Org.). Avanços em políticas de inclusão: o contexto da educação especial no Brasil e em outros países. Porto Alegre: Editora Mediação, 2009. p. 57-78.

REBELO, Andressa Santos; KASSAR, Mônica de Carvalho Magalhães. Escolarização dos alunos da educação especial na política de educação inclusiva no Brasil. Inclusão Social, Brasília, v. 11, n. 1, p. 56-66, jul.-dez. 2017. Disponível em:

http://revista.ibict.br/inclusao/article/view/4079. Acesso em: 10 mar. 2020. 
http://dx.doi.org/10.5902/1984686X49204

RIOS, Elisângela Corrêa. A prática pedagógica do professor de Educação Física nas escolas ribeirinhas do Pantanal Sul-mato-grossense. 2020. Dissertação (Mestrado em Educação) - Universidade Federal de Mato Grosso do Sul, Corumbá, 2020.

SCHMIDT, Carlo. Transtornos do espectro do autismo na escola - protagonismos no processo inclusivo. In: REUNIÃO NACIONAL DA ANPED, 35, 2012, Porto de Galinhas, PE. Anais eletrônicos. Disponível em: http://35reuniao.anped.org.br/images/stories/trabalhos/GT15\%20Trabalhos/GT151786_int.pdf. Acesso em: 15 jul. 2020.

SILVA FILHO, Daniel Mendes da. Acessibilidade: uma análise da existência de barreiras à inclusão de alunos com deficiência/NEE na rede municipal de ensino de Corumbá, MS. Dissertação (Mestrado em Educação) - Universidade Federal de Mato Grosso do Sul, Corumbá, 2017.

\section{UNESCO. Declaración de Salamanca y marco de acción para las necesidades} educativas especiales. Aprobada por la conferencia mundial sobre necesidades educativas especiales: acceso y calidad. Salamanca, España, 7-10 de junio de 1994.

WARNOCK, Mary H. Special educational needs. Report of the Committee of enquiry into the Education of Handicapped Children and Young People. Presented to Parliament by the Secretary of State for Education and Science, the Secretary of State for Scotland and the Secretary of State for Wales by Command of Her Majesty. London: Her Majesty's Stationery Office, 1978.

ZERLOTTI, Patrícia Honorato. Os saberes locais dos alunos sobre o ambiente natural e suas implicações no currículo escolar: um estudo na escola das águas - extensão São Lourenço, no Pantanal de Mato Grosso do Sul. 2014. Dissertação (Mestrado em Educação) - Universidade Católica Dom Bosco, Campo Grande, 2014.

\section{Notas}

1 "Não gosto de palavra acostumada" (BARROS, 2016, p. 52).

2 A expressão foi cunhada, originariamente, no Relatório Warnock (1978) e utilizada na Declaração de Salamanca.

${ }^{3}$ A Lei de Diretrizes e Bases da Educação Nacional (LDB), antes da redação dada pela Lei n. 12.796 de 2013, indicava que a Educação Especial - definida como "modalidade de educação escolar, oferecida preferencialmente na rede regular de ensino" - era destinada "para educandos portadores de necessidades especiais" (BRASIL, 1996). Por sua vez, as Diretrizes Nacionais para a Educação Especial na Educação Básica reiteraram o entendimento da Educação Especial como "modalidade de educação escolar", considerando os "educandos com necessidades educacionais especiais" (BRASIL, 2001).

4 "A educação inclusiva constitui um paradigma educacional fundamentado na concepção de direitos humanos, que conjuga igualdade e diferença como valores indissociáveis, e que avança em relação à idéia de eqüidade formal ao contextualizar as circunstâncias históricas da produção da exclusão dentro e fora da escola" (BRASIL, 2008, p. 1).

5 "A educação especial é uma modalidade de ensino que perpassa todos os níveis, etapas e modalidades, realiza o atendimento educacional especializado, disponibiliza os recursos e serviços e orienta quanto a sua utilização no processo de ensino e aprendizagem nas turmas comuns do ensino regular" (BRASIL, 2008, p. 10). 
http://dx.doi.org/10.5902/1984686X49204

${ }^{6}$ A Política Nacional de Educação Especial, de 1994, já circunscrevia-se ao atendimento de "portadores de deficiência (mental, visual, auditiva, física, múltipla), portadores de condutas típicas (problemas de conduta) e portadores de altas habilidades (superdotação)" (BRASIL, 1994, p. 13).

7 A partir do DSM-V (APA, 2015), a nomenclatura Transtornos do Espectro Autista (TEA) foi criada para abarcar os transtornos globais do desenvolvimento.

8 O AEE é "compreendido como o conjunto de atividades, recursos de acessibilidade e pedagógicos organizados institucional e continuamente, prestado das seguintes formas: I - complementar à formação dos estudantes com deficiência, transtornos globais do desenvolvimento, como apoio permanente e limitado no tempo e na frequência dos estudantes às salas de recursos multifuncionais; ou II - suplementar à formação de estudantes com altas habilidades ou superdotação" (BRASIL, 2011).

${ }^{9}$ As SRM "são ambientes dotados de equipamentos, mobiliários e materiais didáticos e pedagógicos para a oferta do atendimento educacional especializado" (BRASIL, 2011). O AEE ofertado aos alunos PAEE no espaço das SRM deve ocorrer "no turno inverso da escolarização, não sendo substitutivo às classes comuns" (BRASIL, 2009).

$10 \mathrm{O}$ conceito de NEE é amplo, pois abrange "tanto a especificidade do aluno em sua subjetividade como o contexto histórico-cultural em que ele vive e se constitui" (GLAT; BLANCO, 2009, p. 26). Assim, NEE "não é uma característica homogênea fixa de um grupo etiológico também supostamente homogêneo, e sim uma condição individual e específica; em outras palavras, é a demanda de um determinado aluno em relação a uma aprendizagem no contexto em que é vivida" (GLAT; BLANCO, 2009, p. 26, grifos das autoras).

${ }^{11}$ Obtivemos a autorização expressa da Secretaria Municipal de Educação (SEMED) para a realização da pesquisa, a partir da qual tramitamos a proposta na Plataforma Brasil, aprovada com a Certificação de Apresentação para Apreciação Ética - CAAE: 25693219.1.0000.5160.

${ }^{12}$ As últimas visitas estavam agendadas para o final do mês de março de 2020. No entanto, em razão da pandemia de COVID-19, as aulas da REME foram suspensas.

13 Tendo em vista que três foi o número máximo de Professores Regentes entrevistados por unidade de ensino.

${ }^{14}$ Parceria entre a Prefeitura Municipal de Corumbá e o Instituto Acaia (https://www.acaia.org.br/home).

15 Parceria entre a Prefeitura Municipal de Corumbá e o Instituto Rural Escola das Águas - Pantanal do Paiaguás (https://escoladasaguas.org.br/sobre).

${ }^{16}$ Segundo dados dos arquivos da Secretaria das Escolas das Águas.

17 Ao abordar a Educação Especial e a inclusão escolar, o documento faz uso das expressões "estudantes com deficiência, transtornos globais do desenvolvimento e altas habilidades ou superdotação", "alunos com necessidades educacionais especiais" e "alunos com necessidades educativas especiais" (CORUMBÁ, 2015).

${ }^{18}$ Cabe lembrar que no registro das Escolas das Águas também estão computados estudantes sem laudo.

\section{Correspondência}

Washington Cesar Shoiti Nozu - Universidade Federal da Grande Dourados, FAED, Rodovia Dourados - Itahum, Km 12. Caixa Postal 533. Dourados, Mato Grosso do Sul - Brasil.

CEP: $79804-970$

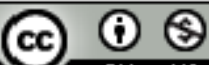

4.0 International (CC BY-NC 4.0) 